Bio-grafía Escritos sobre la Biología y su Enseñanza.

Edición Extra-Ordinaria. ISSN 2027-1034 P. p178-182

Memorias del VII Encuentro Nacional de Experiencias en la Enseñanza de la

Biología y la Educación Ambiental y II Congreso Nacional de Investigación en la Enseñanza de La Biología

\title{
APRENDIENDO DE LA NATURALEZA EN MIRADA BIOMIMETICA Un camino formativo para el desarrollo sostenible
}

\section{LEARNING FROM NATURE THROUGH A BIOMIMICRY FOCUS A formative way for a sustainable development}

\section{Andrés Tamayo Patiño ${ }^{1}$}

\section{Resumen}

¿Qué es formar para la vida? ¿Cuáles son los desafíos contemporáneos para la educación hoy? ¿El mundo productivo es el ámbito teleológico exclusivo que jalona la educación contemporánea? El desafío de respuesta a estas cuestiones exige hoy necesariamente el movilizarse por múltiples ámbitos, que trascienden las cotas de lo económico como extracción, de lo formativo como adquisición de pericias y competencias laborales y de lo ético como circunscrito a la felicidad amarrada a la compre del ultimo tecno facto de moda y se lanzan, en apuestas inciertas, a la búsqueda de fundamentos otros que acogen perspectivas inter, multi, transdisciplinares como ecología, desarrollo sostenible, bioética. La biomimética como mirada alternativa de realidad que redescubre a la naturaleza (todo, incluido el hombre) como la gran maestra para una apuesta de desarrollo sostenible que la imite en sus formas, sus procesos y sus eco-sistemas superando la clasificación de lo natural como recurso y reincorporando al hombre como miembro de lo natural. La biomímesis fundando el PEI, los praes y desplegándose a través de una asignatura optativa de investigación y de un proyecto de semilleros en el currículo de la básica secundaria y la media.

Palabras Claves: la biomímesis como posibilidad de desarrollo sostenible, la biomímesis como alternativa pedagógica; investigación y pares en perspectiva biomimética.

Key Words: Biomimicry and sustainable development; Biomimicry as pedagogic alternative.

\section{Una mirada introductoria}

Hablar de medio ambiente, de ecología, de desarrollo sostenible, de rompimiento de la capa de ozono, de efecto invernadero es asunto cotidiano y de muchos actores. Cada uno de estos conceptos se han convertido en rutina, en clichés, en

\footnotetext{
${ }^{1}$ atpgc2005@gmail.com
} 
Bio-grafia Escritos sobre la Biologia y su Enseñanza.

Edición Extra-Ordinaria. ISSN 2027-1034 P. p178-182

Memorias del VII Encuentro Nacional de Experiencias en la Enseñanza de la

Biología y la Educación Ambiental y 11 Congreso Nacional de Investigación en la Enseñanza de La Biología

asuntos aparentemente gastados por el ingente cumulo de teorías, instituciones, proyectos e inversiones que se gestan a su alrededor; sin embargo, el exceso de datos no obvia su urgencia, su importancia, su interés vital para el hombre de hoy.

Los que hemos apostado nuestras vidas por gestar transformaciones de mundo desde lo formativo estamos pues ante el reto de sentar postura propia frente a estos problemas y desde una puesta/apuesta pedagógica proyectar transformaciones de mundo que incidan, en primera instancia, en un cambio paradigmático, en el transito hacia miradas ampliadas que funden con deontos, sendas y telos otras posibilidades del estando/siendo humano en la tierra trascendiendo el paradigma de occidente asentado en el capitalismo, la economía extractiva y la colonización neo liberal.

Un segundo movimiento nos lleva, después de la deconstrucción del imaginario moderno, a presentar en diferencia, como alternativa de otredad, una propuesta de mundo que permita reintegrar al hombre, en su potencia y en sus limites, al ámbito de la naturaleza(Noguera,2004) del cual se había distanciado en romería conceptual, disolviendo la dualidad polarizante cartesiana de la res cogitans versus res extensa para visibilizar el oikos (hogar)como poli sistemas articulados de lo bio y lo abio, donde lo humano se une dialógicamente (en contradicción, complementariedad y concurrencia; (Morin , 2006) con las otras especies. El ser humano entronizado en los albores de lo moderno y obnubilado por el endiosamiento de la ciencia, el método científico y la objetividad regresa al seno, pero ya no como centro, sino como nodo entre múltiples nodos de la trama maravillosa de la vida (Capra, 1996) en los multiversos de la Gaia.

La especie humana encumbrada, exaltada ha asumido por diversos motivos, la dominancia y el privilegio de regir el planeta y desde su potencia ha logrado grandes y maravillosas construcciones; sin embargo su "aparente progreso" se extiende solo a algunas esferas y no alcanza a cubrir otras dimensiones de lo humano; así, por ejemplo, se han logrado grandes éxitos en medicina, en producción de tecno-factos, en las TICs... pero los grandes problemas del hombre permanecen: la pobreza y los procesos de pauperización en crecimiento, la violencia, la inequidad. Y a éstos de siempre se aúnan los ya mencionados en relación con los daños causados al hogar (la tierra) por la aplicación inmisericorde de una economía de lucro. La magnitud de las dificultades de hoy parecen superar las potencialidades de lo humano y sus más grandes inventos. Emerge, calladamente en principio, pero cada vez con más fuerza el reconocernos, el mirarnos y tomar consciencia de nuestra paradoja: somos unidad dialógica de lo grande y lo nimio, somos sujetos de posibilidades, pero, a la vez, somos y estamos en situación límite: no somos omnipotentes. 
Bio-grafia Escritos sobre la Biologia y su Enseñanza.

Edición Extra-Ordinaria. ISSN 2027-1034 P. p178-182

Memorias del VII Encuentro Nacional de Experiencias en la Enseñanza de la

Biología y la Educación Ambiental y 11 Congreso Nacional de Investigación en la Enseñanza de La Biología

Es desde esta postura de reconocimiento que redescubrimos a los otros en el hogar, como habitantes con ellos de un planeta en urgencia, y en humildad optamos por aprender de esos otros, de unirnos, de hacer sinergia, de gestar simbiosis en pro de la posibilidad de un presente y de un futuro.

\section{Apuestas contextuales}

En la Institución Educativa Juan Pablo II ubicada en la zona rural de Manizales, vereda Alto el Guamo, corregimiento el Manantial hemos asumido como desafío formar-nos para dar respuestas a los problemas del presente: educandos, educadores, padres de familia en búsqueda de nuevas formas de con-vivencia en el planeta, con desarrollo sostenible y en pro de un buen vivir que garantice un despliegue humano multi dimensional. En consecuencia con nuestra apuesta progresiva y paulatinamente hemos ido reconfigurando-nos y re-configurando el PEI y los proyectos de la Institución de manera tal que quienes interactuamos en los ámbitos escolares nos transformemos y transformemos nuestros contextos (familiares, sociales, económicos, culturales) en pro de escenarios del presente y del futuro más humanos.

BIOMIMESIS (Asunto de metódicas): Un proyecto con trayecto y un trayecto con proyecto.

La Institución educativa Juan Pablo II ubicada en la vereda Alto el guamo, corregimiento el Manantial, municipio de Manizales asume en su PEl y sus proyectos pedagógicos de acuerdo con las características geográficas, culturales, sociales y económicas de sus entornos una perspectiva agro industrial que pretende el desarrollo de competencias humanas, sociales y laborales que incidan en el mejoramiento de las condiciones de vida de la comunidad educativa, en su mayoría de carácter rural. En pro de ello su enfoque pedagógico transita con el modelo Escuela Nueva desarrollando proyectos productivos de seguridad alimentaria con el apoyo de la alianza y el SENA.

Buscando un sustento teórico que alimente, sustente y oriente el énfasis formativo de la Institución nos hemos apostado en la exploración e implementación de una mirada de mundo denominada por su creadora, Janine benyus, como biomímesis o biomimética; definiéndola, Benyus, nos dice : "la biomímesis es una nueva ciencia que estudia los modelos de la naturaleza para imitar o inspirarse en los diseños y procesos biológicos para resolver problemas humanos" (2012). Afirma también: "A diferencia de la revolución industrial...la revolución biomimética inaugura una era basada no en lo que podemos extraer de la naturaleza, sino en lo que podemos aprender de ella". 
Bio-grafia Escritos sobre la Biología y su Enseñanza.

Edición Extra-Ordinaria. ISSN 2027-1034 P. p178-182

Memorias del VII Encuentro Nacional de Experiencias en la Enseñanza de la

Biología y la Educación Ambiental y 11 Congreso Nacional de Investigación en la Enseñanza de La Biología

Comprometidos con esta mirada hemos ido implementando bases pedagógicas y didácticas que nos posibiliten impregnar con los principios de la biomímesis todos los ámbitos de la vida escolar y, través de ella, los multi-versos de despliegue de los miembros de la comunidad educativa.

Pretendemos vivir la biomímesis como fuente, sustento y telos del ser-quehacer de la Institución y a tal fin hemos realizado las siguientes acciones:

En el 2012 se instituyo en nuestro colegio la asignatura de "Investigación" con la pretensión de recuperar en nuestros educandos la capacidad de asombro, curiosidad y sorpresa y ejercitarlos en las lides del proceso investigativo en pro de desplegar su pericia como investigadores. A lo largo del año anterior y del corriente se ha ido progresando en la construcción de un proceso formativo en investigación utilizando guías de aprendizaje propias de acuerdo a los momentos de la metodología Escuela Nueva. Hasta el momento se han acentuado las reflexiones en torno a la problematización de los entornos y la construcción de preguntas.

Reconfiguración del PRAE en torno a la mirada biomimética.

Utilizando el ámbito de la asignatura de investigación articulada a las de seguridad alimentaria, ciencias naturales y emprendimiento se constituyen dos semilleros de investigación: semillero biomimética con estudiantes de los grados 10 y 11 y semillero el manantial conformado por educandos de los grados $8^{\circ}$ y $9^{\circ}$.

Selección de problemas de investigación: la contaminación ambiental manifiesta en la presencia de olores y gases y de sustancias de desecho en una quebrada vecina posibilito el orientar el proceso de investigación formativo hacia la búsqueda de formas, métodos de purificación de aguas desde miradas biomiméticas. Este proyecto se encuentra en la fase de planificación ya que si bien, se espera un resultado, lo fundamental en el momento es el proceso de indagación como mecanismo para aprender a investiga al lado de un investigador.

Se genera así un bucle espiralado en el que las asignaturas de investigación, emprendimiento, seguridad alimentaria y ciencias naturales se articulan al Prae y el PEI del colegio en un entorno que se funda en los principios y elementos de la biomímesis.

La asignatura de investigación aporta los elementos del método científico; las ciencias naturales los medios de depuración de agua; el PRAE los principios de la biomímesis, el emprendimiento desarrolla competencias específicas en torno a destrezas concretas como el manejo de aguas. 
Bio-grafía Escritos sobre la Biología y su Enseñanza.

Edición Extra-Ordinaria. ISSN 2027-1034 P. p178-182

Memorias del VII Encuentro Nacional de Experiencias en la Enseñanza de la

Biología y la Educación Ambiental y II Congreso Nacional de Investigación en la Enseñanza de la Biología

En el mes de junio la Institución educativa Juan Pablo II realizo el II Simposio Construyendo Pensamiento Ambiental en la Escuela rural en perspectiva Biomimética con la participación de ponentes de varias universidades de la región con el fin de visibilizar nuestro colegio y la mirada de la biomímesis.

\section{Cierre-Apertura}

La puesta/apuesta de nuestro colegio se incorpora y anuda a múltiples esfuerzos que calladamente crecen en América Latina y en el mundo en pro de la gesta de humanas condiciones en relación compleja (del todo a la parte y de la parte al todo) con todas las especies que co-existimos en este hogar llamado tierra.

Creemos desde nuestro territorio en la posibilidad de un buen vivir, de un desarrollo sostenible que superando la mirada reduccionista de la tierra como recurso y del hombre como señor podemos instaurar una equidad terrenal, una ética global, un mundo mejor.

Como muchos otros vivimos en micro resistencia respecto a quienes hanoptado por extraer destruyendo, gestando miseria y manteniendo la inequidad en pro de la conservación de sus privilegios. Pero nuestra resistencia es pacífica y se mueve en los límites de lo humano, de lo ético, de la naturaleza. Somos sembradores de esperanza y constructores del presente: Creemos que la biomímesis es una posibilidad de respuesta, a la vez que es fuente de mil preguntas, para afrontar los retos del hoy de nuestras vidas.

\section{Bibliografía}

- Benyus Janine. BIOMIMESIS. Como la ciencia innova inspirándose en la naturaleza. Metatemas, 2012.

- Capra Fritjoj. La trama de la Vida. Anagrama, 1996.

- Morin Edgar. El método I. catedra, 2006.

- Noguera de Echeverri, Ana Patricia. El reencantamiento del mundo. Universidad Nacional de Colombia, 2004. 